\title{
Unsteady Electrohydrodynamic Stagnation Point Flow of Hybrid Nanofluid Past a Convective Heated Stretch/Shrink Sheet
}

\author{
Muhammad Jawad, ${ }^{1}$ Rashid Jan, ${ }^{1}$ Salah Boulaaras $\mathbb{D}^{2,3}$ Ibni Amin, ${ }^{4}$ Niaz Ali Shah, ${ }^{1}$ \\ and Sahar Ahmed Idris ${ }^{5,6}$ \\ ${ }^{1}$ Department of Mathematics, University of Swabi, Swabi 23561, KPK, Pakistan \\ ${ }^{2}$ Department of Mathematics, College of Sciences and Arts, ArRass, Qassim University, Saudi Arabia \\ ${ }^{3}$ Laboratory of Fundamental and Applied Mathematics of Oran (LMFAO), University of Oran 1, Oran, Algeria \\ ${ }^{4}$ Department of Mathematics, Abdul Wali Khan University, Mardan, 23200 Khyber Pakhtunkhwa, Pakistan \\ ${ }^{5}$ College of Industrial Engineering, King Khalid University, Abha 61471, Saudi Arabia \\ ${ }^{6}$ Department of Mathematics, College of Sciences, Juba University, Sudan
}

Correspondence should be addressed to Sahar Ahmed Idris; sa6044690@gmail.com

Received 26 August 2021; Accepted 11 October 2021; Published 29 October 2021

Academic Editor: David Carf

Copyright (c) 2021 Muhammad Jawad et al. This is an open access article distributed under the Creative Commons Attribution License, which permits unrestricted use, distribution, and reproduction in any medium, provided the original work is properly cited.

\begin{abstract}
Unsteady electrohydrodynamic hybrid nanofluid $\left(\mathrm{Al}_{2} \mathrm{O}_{3}-\mathrm{Cu} / \mathrm{H}_{2} \mathrm{O}\right)$ past a convective heat stretched/shrinked sheet is examined. A stagnation point fluid flow with velocity slip constrains and heat source or sink is deliberated. The combined set of PDEs is translated into ODEs by including approved similarity transformations. HAM is applied for the solution to the obtained nonlinear system. The magnetic input factor, Prandtl number, electric field factor, Eckert number, heat source factor, and unstable factor are the governing parameters. The impact of these factors on the temperature and velocity profiles features of the problem is considered with explanation. Intensification in values of electric and magnetic fields parameters enhanced the heat transfer rate. The greater Prandtl number lessens the temperature. Amplification in temperature is perceived for Eckert parameter. The heat transferred rate of hybrid nanofluid in the entire domain increases as the heat source increases, while the heat sink has the opposite effect. Skin friction and Nusselt number is increased for increasing values of magnetic field parameters. It is also noted that Nusselt number lessens for raising in $\operatorname{Pr}, E$, and Ec. Furthermore, it is eminent that the hybrid nanofluid possesses better result compared to the nanofluid.
\end{abstract}

\section{Introduction}

The ability of nanofluids to improve heat transfer performance in a range of industrial applications due to the substantial raise in thermal conductivity of the resulting fluid has piqued interest in recent years. A liquid in which nanosized metallic or nonmetallic components are suspended is defined as this new class of fluids. By dispersing a composite nanopowder or various types of nanoparticles in the hybrid nano- and base fluids, which are a continuation of nanofluids, can be created. An enhanced nanofluid having two distinct nanoparticles scattered in the base fluid is called a hybrid nanofluid.
Many researchers have been interested in studying heat source in a hybrid nanofluid in recent years because of its ability to boost heat transfer rates when compared to ordinary nanofluid. As a result, most heat transferring uses, such as transformer cooling, electronic cooling, and coolant in machines, have used hybrid nanofluid as the heat source fluid. Nanofluid is an eminent as a high heat transferred when compared to other fluids. The hybrid nanofluid, on the other hand, is researched in this study is to strengthen the rate of heat source of the standard nanofluid. Several scientists used numerical methods to explore the heat transport and the boundary layering flow of a hybrid nanofluid. The researchers in [1] studied the flow of a hybrid nanofluid past 
a stretched sheet by considering $\mathrm{Cu}-\mathrm{Al}_{2} \mathrm{O}_{3}$ nanoparticles with magnetic impacts. Newtonian heated condition was examined by these researchers with the 3-D flow [2]. The rate of heat transferring of hybrid nanofluid was found to be greater than that of standard nanofluid. Hayat and Nadeem [3] considered the rotating flow of hybrid nanofluid which consisted of Ag$\mathrm{CuO} /$ water. The authors in [4] conceptualize and investigate the flow of hybrid nanofluid over an unsteady stagnation point convective heat stretch/shrink surface including the velocity slip impact on heat transfer. Using the Buongiorno model, Daniel et al. [5] analyzed and interrogated mixed convection electrico MHD flow and heat source caused nano-fluid over a permeable stretched surface. Xie et al. [6] worked out on the friction coefficient and wear volume of hybrid nanoparticles to determine their tribological properties of the $\mathrm{SiO}_{2} / \mathrm{Mo}$ $\mathrm{S}_{2}$. When compared to pure nanofluids, they found that hybrid nanofluids have a smaller friction coefficient and wear volume. The authors in [7] scrutinized the impact of nanoparticle concentration and temperature distribution on rheological performance of $\left(\mathrm{Fe}_{3} \mathrm{O}_{2}-\mathrm{Ag} / \mathrm{EG}\right)$ hybrid nanofluid.

Ghadikolaei et al. [8] examined the thermophysical possessions of $\left(\mathrm{TiO}_{2}-\mathrm{Cu} / \mathrm{H}_{2} \mathrm{O}\right)$ with a shape factor with Lorentz forces. Hussian et al. [9] considered hybrid nanofluid containing $\left(\mathrm{Al}_{2} \mathrm{O}_{3}-\mathrm{Cu} / \mathrm{H}_{2} \mathrm{O}\right)$ and proved excellent results in the circumstance of their assumptions. They calculated numerical solutions using the finite element scheme and analyzed the impact of various input factors on the hybrid nanofluids. Magnetohydrodynamic (MHD) has recently gotten prominent attention due to its wide range of applications in geophysics, petroleum, chemical technology, environmental, engineering, and many other branches of science and technology. The Lorentz force which is also known as the drag force produced through the magnetic field that is used by MHD. Waqas et al. [10] investigated non-Newtonian liquid MHD mixed convection flow of fluid on stretched and nonlinear surface. Furthermore, the impact of magnetic field heat transferred of nanofluids in microchannels was discussed by the researchers in their research [11]. Other researchers also worked out in this area and produced a significant work in the field [12-14].

Scientists are interested in the stretching surface because of its numerous uses in engineering domains such as glass blowing, polymer extrusion, fast spray, wire drawing, quenching in metal foundries, and microelectronics cooling. The theoretical boundary layer flows over stretched sheet has been scrutinized by Crane [15]. Different authors investigated the exponentially stretching sheet [16-19], the main applications in technology and industry. In everyday life and industrial challenges, the exponentially shrinked/stretched sheet is often used with fluid flow and heat transmission. The article by Magyari and Keller [20] appears to be the first to investigate at the fluid boundary layer flow on an exponentially stretched sheet. The exponential similarity variables were used by Mushtaq et al. [21] to turn the controlling PDEs into ODEs. Furthermore, the researchers in [22] interrogated the mixed convective flow of nanofluid and obtained excellent result and find out the influence of input parameter in the flow. The MHD fluid flow for the stagnation point was created by Rahman et al.
[23], who employed exponential similarity variables to generate ODEs.

Fluid movement near a solid surface's stagnation area is explained by the stagnation point flow. Hiemenz [24] was the first to inspect stagnation-point flow problem in a flowing fluid over a fixed surface. Homann [25] then enlarged to a 3-D stagnation-point flow problem in the axis symmetric condition. The researcher in [26] reported a stagnation fluid flow in a diminishing surface. According to him, the presence of a stagnation fluid flow velocity can constrain the vorticity to maintain the flow, eliminating the need for suction on the shrinked sheet. Many academics have studied numerous influences on flow behavior by extending the stagnationpoint flow problem. This problem is further investigated by Bachok et al. [27] without and with heat transferred where the authors discovered the decreasing case's solutions are no unique and that increasing the melting parameter reduces the heat source rate at the solid-fluid interface. In 1992, Liao [28] discovered that this method was a faster technique to get approximated solution and that it was a better fit for solving nonlinear problems. Several researchers contributed to find the solution through a homotopy analysis scheme (HAM) [29-32]. The reader can further study about heat transfer through nanofluid flow in Refs. [33-40].

The target of this work is to look into the combined impact of magnetic field, heat generation/absorption, electric field, and velocity slip parameter for unstable stagnation-point flow of electrical conducting hybrid nanofluids with the velocity slip input factor. In addition to this, we will focus on the stability of the system. As a result of the aforementioned issues, the researchers decided to interrogate the unstable stagnation-point flow towards a convective heated stretched or shrinked surface in alumina-copper/water $\left(\mathrm{Al}_{2} \mathrm{O}_{3}-\mathrm{Cu} / \mathrm{H}_{2} \mathrm{O}\right)$ to see how velocity slip affects heat transfer. To decrease the independent variables in governing equations resulting from mathematical modelling, a suitable set of dimensionless variables is utilised. By applying the homotopy method, an analytical solution has been computed.

\section{Mathematical Formulation}

This research considers the unstable 2-D stagnation point flow of a hybrid system $\left(\mathrm{Al}_{2} \mathrm{O}_{3}-\mathrm{Cu} / \mathrm{H}_{2} \mathrm{O}\right)$ nanofluid over a convective heated stretched or shrinked surface with the impact of velocity slip. In our formulation, the term $u_{w}(x, t$ )$=b x /(1-c t)$ is the stretched/shrinked velocity in which $b$ represent a fix association with shrinked $(b<0)$ and stretched $(b>0)$. We have the following cases while $c$ denotes the unsteadiness problem and the velocity of the free stream is defined by $u_{e}(x, t)=a x /(1-c t)$. Here, $a>0$ indicates the power of the stagnation flow. $T_{1}$ and $T_{0}$ are the ambient temperature and the reference temperature, respectively. Further, heat is provided to it with some specific temperature given by $T_{f}(x, t)=T_{1}-T_{0}\left(a x^{2} / 2 v\right)(1-c t)^{-3 / 2}$ which provided a heat transferred coefficient, denoted by $h_{f}$. Then, the governing equation of [4] with all our 
assumptions is as follows:

$$
\begin{gathered}
\frac{\partial u}{\partial x}+\frac{\partial u}{\partial y}=0 \\
\frac{\partial u}{\partial t}+u \frac{\partial u}{\partial x}+v \frac{\partial u}{\partial y}=\frac{\partial u_{e}}{\partial t}+\mu_{e} \frac{\partial u_{e}}{\partial x}+\frac{\mu_{\mathrm{hnf}}}{\rho_{\mathrm{hnf}}} \frac{\partial^{2} u}{\partial y^{2}}+\frac{\sigma_{\mathrm{hnf}}}{\rho_{\mathrm{hnf}}}\left(E_{0} B_{0}-B_{0}^{2} u\right), \\
\frac{\partial T}{\partial t}+u \frac{\partial T}{\partial x}+v \frac{\partial T}{\partial y}=\frac{k_{\mathrm{hnf}}}{\left(\rho c_{p}\right)_{\mathrm{hnf}}} \frac{\partial^{2} T}{\partial y^{2}}+\frac{\sigma_{\mathrm{hnf}}}{\left(\rho c_{p}\right)_{\mathrm{hnf}}}\left(u B_{0}-E_{0}\right)^{2} \\
+\frac{Q_{0}}{\left(\rho c_{p}\right)_{\mathrm{hnf}}}\left(T-T_{\infty}\right),
\end{gathered}
$$

where $u$ and $v$ indicated the velocity components along the $x$-axis and along the $y$-axis, respectively, while the dynamic viscosity is indicated by $\mu_{\text {hnf }}, T$ is the $\mathrm{Al}_{2} \mathrm{O}_{3}-\mathrm{Cu} /$ $\mathrm{H}_{2} \mathrm{O}$ temperature, $\rho_{\text {hnf }}$ is the density of $\mathrm{Al}_{2} \mathrm{O}_{3}-\mathrm{Cu} / \mathrm{H}_{2} \mathrm{O}, k_{\text {hnf }}$ is the conductivity of thermal/heat of $\mathrm{Al}_{2} \mathrm{O}_{3}-\mathrm{Cu} / \mathrm{H}_{2} \mathrm{O}$, and $\left(\rho c_{p}\right)_{\text {hnf }}$ is the $\mathrm{Al}_{2} \mathrm{O}_{3}-\mathrm{Cu} / \mathrm{H}_{2} \mathrm{O}$ heat capacity.

$$
\begin{gathered}
u=u_{w}(x, t)+H_{1} v \frac{\partial u}{\partial y}, v=0,-k_{h n f} T_{y}=h_{f}\left(T_{f}-T\right) \text { at } y=0, \\
u \longrightarrow u_{e}(x, t), T \longrightarrow T_{\infty} \text { at } y \longrightarrow \infty
\end{gathered}
$$

The above given Equation (4) show the Bcs, together with the partial slip for velocity component, the velocity slip factor is $H_{1}=H(1-c t)^{1 / 2}$, where the initial value of the velocity slip parameter has been denoted by $H$. The properties of copper $(\mathrm{Cu})$ thermophysical along with water $\left(\mathrm{H}_{2} \mathrm{O}\right)$ nanoparticles and with aluminum oxide $\left(\mathrm{Al}_{2} \mathrm{O}_{3}\right)$ have been presented in Table 1 . In the meantime, the thermophysical properties of hybrid nanofluid were published in Table 2. All the related input factors and symbols are represented in the nomenclature with detailed description.

To simplify the abovementioned problem represented in Equations (1)-(3) along with condition (4), we take the following similarity transformations [4]:

$\psi=\left(\frac{a v}{1-c t}\right)^{1 / 2} x f(\eta), \theta(\eta)=\frac{T-T_{\infty}}{T_{f}-T_{\infty}}, \eta=\left(\frac{a}{v(1-c t)}\right)^{1 / 2} y$

In the above, $\eta$ is the similarity variable and $u=\partial \psi / \partial y$ and $v=-\partial \psi / \partial x$ are satisfied through the stream function $\psi$ ; thus, we get the following:

$$
u=\frac{a x}{1-c t} f^{\prime}(\eta), v=-\left(\frac{a v}{1-c t}\right)^{1 / 2} f(\eta)
$$

In the case, when the similarity variables (5) and (6) are employed to (2) and (3), they are converted to the following equations:

$$
\begin{aligned}
\frac{\mu_{\mathrm{hnf}} / \mu_{f}}{\rho_{\mathrm{hnf}} / \rho_{f}} f^{\prime \prime \prime} & +2 f f^{\prime \prime}-f^{\prime 2}+1-\varepsilon\left(f^{\prime}-\frac{1}{2} \eta f^{\prime \prime}-1\right) \\
& +\frac{\sigma_{\mathrm{hnf}} / \sigma_{f}}{\rho_{\mathrm{hnf}} / \rho_{f}} M\left(E-f^{\prime}\right)=0,
\end{aligned}
$$

$$
\begin{gathered}
\frac{1}{\operatorname{Pr}} \frac{k_{\mathrm{hnf}} / k_{f}}{\left(\rho c_{p}\right)_{\mathrm{hnf}} /\left(\rho c_{p}\right)_{f}} \theta^{\prime \prime}+f \theta^{\prime}-2 f^{\prime} \theta+\frac{\varepsilon}{2}\left(\eta \theta^{\prime}+3 \theta\right) \\
\quad+\frac{\sigma_{\mathrm{hnf}} / \sigma_{f}}{\left(\rho c_{p}\right)_{\mathrm{hnf}} / \rho_{f}} \operatorname{MEc}\left(f^{\prime}-E\right)+\frac{Q\left(\rho c_{p}\right)_{f}}{\left(\rho c_{p}\right)_{\mathrm{hnf}}} \theta=0 .
\end{gathered}
$$

After that, the beginning and boundary constrain (4) becomes

$$
\begin{gathered}
f(0)=0, f^{\prime}(0)=\lambda+\gamma f^{\prime \prime}(0),-\frac{k_{\mathrm{hnf}}}{k_{f}} \theta^{\prime}(0)=B i[1-\theta(0)], \\
f^{\prime}(\eta) \longrightarrow 1, \theta(\eta) \longrightarrow 0, \text { while } \eta \longrightarrow \infty
\end{gathered}
$$

Where $\varepsilon, M, E, \mathrm{Ec}, \mathrm{Pr}, \mathrm{Bi}, \mathrm{Re}_{x}, \lambda$, and $Q \quad$ unsteadiness parameter, magnetic parameter, ELECTRIC FIELD PARAMETER, Eckert number, local Reynolds number in the $x$-axis, Biot number, Prandtl number, ratio of velocity parameter, and heat source/sink parameter.

$$
\begin{gathered}
\lambda=\frac{G_{r}}{\operatorname{Re}_{x}^{2}}, \\
\varepsilon=\frac{b}{a}, \\
\operatorname{Re}_{x}=\frac{a x^{2}}{v_{f}}, \\
\operatorname{Pr}=\frac{\nu_{f}}{\alpha}, \\
M=\frac{\sigma \beta_{0}^{2}}{\rho_{f} a}, \\
\mathrm{Bi}=\frac{h_{f}}{k \sqrt{\frac{\nu_{f}}{a}},} \\
\mathrm{Ec}=\frac{a x^{2}}{c_{p} \Delta T}, \\
Q_{0}(1-c t)^{2} \\
E=\frac{E_{0}}{\beta_{0} a x} .
\end{gathered}
$$


TABLE 1: Illustration of thermo-physical properties of $\mathrm{Al}_{2} \mathrm{O}_{3}, \mathrm{H}_{2} \mathrm{O}$, and $\mathrm{Cu}$ [4].

\begin{tabular}{lccr}
\hline Thermophysical properties & $\mathrm{Cu}$ & $\mathrm{Al}_{2} \mathrm{O}_{3}$ & $\mathrm{H}_{2} \mathrm{O}$ \\
\hline$c_{p}(\mathrm{~J} / \mathrm{kgK})$ & 385 & 765 & 4179 \\
$\rho\left(\mathrm{kg} / \mathrm{m}^{3}\right)$ & 8933 & 3970 & 9971 \\
$k(\mathrm{~W} / \mathrm{mK})$ & 400 & 40 & 0.613 \\
$\beta \times 10^{5}(1 / \mathrm{K})$ & 1.67 & 0.85 & 21 \\
\hline
\end{tabular}

TABLe 2: Applied models for thermophysical properties of the hybrid nanofluid [4].

\begin{tabular}{|c|c|}
\hline Property & Hybrid nanofluid \\
\hline $\begin{array}{l}\text { Thermal } \\
\text { capacity }\end{array}$ & $\left(\rho c_{p}\right)_{\mathrm{hnf}}=\left(1-\phi_{\mathrm{hnf}}\right)\left(\rho c_{p}\right)_{f}+\phi_{1}\left(\rho c_{p}\right)_{s 1}+\phi_{2}\left(\rho c_{p}\right)_{s 2}$ \\
\hline Density & $\rho_{\mathrm{hnf}}=\left(1-\phi_{\mathrm{hnf}}\right) \rho_{f}+\phi_{1} \rho_{s 1}+\phi_{2} \rho_{s 2}$ \\
\hline Viscosity & $\mu_{\mathrm{hnf}}=1 /\left(1-\phi_{\mathrm{hnf}}\right)^{2.5}$ \\
\hline $\begin{array}{l}\text { Thermal } \\
\text { conductivity }\end{array}$ & $k_{\mathrm{hnf}} / k_{f}=\left[\left(\left(\phi_{1} k_{s 1}+\phi_{2} k_{s 2}\right) / \phi_{\mathrm{hnf}}\right)+2 k_{f}+2\left(\phi_{1} k_{s 1}+\phi_{2} k_{s 2}\right)-2 \phi_{\mathrm{hnf}} k_{f} /\left(\left(\phi_{1} k_{s 1}+\phi_{2} k_{s 2}\right) / \phi_{\mathrm{hnf}}\right)+2 k_{f}-2\left(\phi_{1} k_{s 1}+\phi_{2} k_{s 2}\right)-\phi_{\mathrm{hnf}} k_{f}\right]$ \\
\hline
\end{tabular}

\section{Physical Quantities of Interest}

For the above model, we take the coefficient of skin friction $\left(c_{f}\right)$ and local Nusselt number $\left(N u_{x}\right)$ as follows:

$$
\begin{gathered}
C_{f}=\frac{\tau_{w}}{\rho_{f} u_{e}^{2}}, \\
N u_{x}=\frac{x q_{w}}{k_{f}\left(T_{f}-T_{\infty}\right)} .
\end{gathered}
$$

In which

$$
\begin{gathered}
\tau_{w}=\mu_{\mathrm{hnf}}\left(\frac{\partial u}{\partial y}\right)_{y=0}, \\
q_{w}=-\left.k_{\mathrm{hnf}}\left(\frac{\partial T}{\partial y}\right)\right|_{y=0} .
\end{gathered}
$$

The dimensional form of the above is

$$
\begin{gathered}
{\left[R_{e x}\right]^{1 / 2} C_{f}=\frac{\mu_{\mathrm{hnf}}}{\mu_{f}} f^{\prime \prime}(0),} \\
{\left[R_{e x}\right]^{-1 / 2} N u_{x}=-\frac{k_{\mathrm{hnf}}}{k_{f}} \theta^{\prime}(0) .}
\end{gathered}
$$

\section{Solution by HAM}

In this section of the paper, HAM will be used to solve Equations (7) and (8) with boundary conditions (9). Mathematica software is utilized for this purpose. The basic HAM derivation is given as follows:

$$
L_{\widehat{f}}(\widehat{f})=\widehat{f}^{\prime \prime \prime}-\widehat{f}^{\prime}, L_{\widehat{\theta}}(\widehat{\theta})=\widehat{\theta}^{\prime \prime}-\widehat{\theta}
$$

Linear operators $L_{\widehat{f}}$ and $\mathrm{L}_{\widehat{\theta}}$ are specified by

$$
L_{\widehat{f}}\left(\gamma_{1}+\gamma_{2} e^{-\eta}+\gamma_{3} e^{\eta}\right)=0, L_{\widehat{\theta}}\left(\gamma_{4} e^{-\eta}+\gamma_{5} e^{\eta}\right)=0
$$

The nonlinear operators $N_{\widehat{f}}$ and $N_{\widehat{\theta}}$ are as follows:

$$
\begin{aligned}
N_{\widehat{f}}[\widehat{f}(\eta ; \zeta)]=\frac{\mu_{\mathrm{hnf}} / \mu_{f}}{\rho_{\mathrm{hnf}} / \rho_{f}} \widehat{f}_{\eta \eta \eta}+2 \widehat{f}_{\hat{f}}-\widehat{f}_{\eta}^{2}+1 \\
-\varepsilon\left(\widehat{f}_{\eta}-\frac{1}{2} \eta \widehat{f}_{\eta \eta}-1\right)+\frac{\sigma_{\mathrm{hnf}} / \sigma_{f}}{\rho_{\mathrm{hnf}} / \rho_{f}} M\left(E-\widehat{f}_{\eta}\right), \\
N_{\widehat{\theta}}[\widehat{f}(\eta ; \zeta), \widehat{\theta}(\eta ; \zeta), \widehat{\phi}(\eta ; \zeta)] \\
=\frac{1}{\operatorname{Pr}} \frac{k_{\mathrm{hnf}} / k_{f}}{\left(\rho c_{p}\right)_{\mathrm{hnf}} /\left(\rho c_{p}\right)_{f}} \widehat{\theta}_{\eta \eta}+\widehat{f} \widehat{\theta}_{\eta}-2 \widehat{f}_{\eta} \widehat{\theta} \\
+\frac{\varepsilon}{2}\left(\eta \widehat{\theta}_{\eta}+3 \widehat{\theta}\right)+\frac{\sigma_{\mathrm{hnf}} / \sigma_{f}}{\left(\rho c_{p}\right)_{\mathrm{hnf}} / \rho_{f}} M \operatorname{MEc}\left(\widehat{f}_{\eta}-E\right) \\
+\frac{Q\left(\rho c_{p}\right)_{f}}{\left(\rho c_{p}\right)_{\mathrm{hnf}}} \widehat{\theta}
\end{aligned}
$$

For Equations (7) and (8), we have shown the $0^{\text {th }}$-order system as

$$
\begin{gathered}
(1-\zeta) L_{\widehat{f}}\left[\widehat{f}(\eta ; \zeta)-\widehat{f}_{0}(\eta)\right]=p \hbar_{\hat{f}} N_{\widehat{f}}[\widehat{f}(\eta ; \zeta)] \\
(1-\zeta) L_{\widehat{\theta}}\left[\widehat{\theta}(\eta ; \zeta)-\widehat{\theta}_{0}(\eta)\right]=p \hbar_{\widehat{\theta}} N_{\widehat{\theta}}[\widehat{\theta}(\eta ; \zeta), \widehat{f}(\eta ; \zeta)] .
\end{gathered}
$$


The $\mathrm{BCs}$ are:

$$
\begin{gathered}
\left.\widehat{f}(\eta ; \zeta)\right|_{\eta=0}=0,\left.\frac{\partial \widehat{f}(\eta ; \zeta)}{\partial \eta}\right|_{\eta=0}=\lambda+\gamma \widehat{f}_{\eta \eta}(0), f(0)=0, \\
\left.\quad \frac{k_{n f}}{k_{f}} \frac{\partial \widehat{\theta}(\eta ; \zeta)}{\partial \eta}\right|_{\eta=0}=-B i(1-\widehat{\theta}(0)), \\
\left.\frac{\partial \widehat{f}(\eta ; \zeta)}{\partial \eta}\right|_{\eta=\infty} \longrightarrow 1,\left.\widehat{\theta}(\eta ; \zeta)\right|_{\eta=\infty} \longrightarrow 0
\end{gathered}
$$

While the embedded constraint is $\zeta \in[0,1], \hbar_{\widehat{f}}$ and $\hbar_{\widehat{\theta}}$ are utilized to regulate the convergence. When $\zeta=0$ and $\zeta=1$, we have

$$
\widehat{f}(\eta ; 1)=\widehat{f}(\eta), \widehat{\theta}(\eta ; 1)=\widehat{\theta}(\eta),
$$

After that, $\widehat{f}(\eta ; \zeta)$ and $\widehat{\theta}(\eta ; \zeta)$ are expended through Taylor's expansion for $\zeta=0$ :

$$
\begin{gathered}
\widehat{f}(\eta ; \zeta)=\widehat{f}_{0}(\eta)+\sum_{n=1}^{\infty} \widehat{f}_{n}(\eta) \zeta^{n}, \\
\widehat{\theta}(\eta ; \zeta)=\widehat{\theta}_{0}(\eta)+\sum_{n=1}^{\infty} \widehat{\theta}_{n}(\eta) \zeta^{n}, \\
\widehat{f}_{n}(\eta)=\left.\frac{1}{n !} \frac{\partial \widehat{f}(\eta ; \zeta)}{\partial \eta}\right|_{p=0}, \\
\widehat{\theta}_{n}(\eta)=\left.\frac{1}{n !} \frac{\partial \widehat{\theta}(\eta ; \zeta)}{\partial \eta}\right|_{p=0} .
\end{gathered}
$$

The BCs are

$$
\begin{gathered}
\widehat{f}(0)=0, \widehat{f^{\prime}}(0)=\lambda+\gamma \widehat{f}^{\prime \prime}(0), \frac{k_{\mathrm{hnf}}}{k_{f}} \widehat{\theta^{\prime}}(0)=-B i(1-\widehat{\theta}(0)) \\
\widehat{f^{\prime}}(\eta) \longrightarrow 0, \widehat{\theta}(\eta) \longrightarrow 0, \eta \longrightarrow \infty .
\end{gathered}
$$

Now,

$$
\begin{aligned}
\mathfrak{R}_{n}^{\hat{f}}(\eta)= & \frac{\mu_{\mathrm{hnf}} / \mu_{f}}{\rho_{\mathrm{hnf}} / \rho_{f}} \widehat{f}_{n-1}^{\prime \prime \prime}+2 \sum_{j=0}^{w-1} \widehat{f}_{w-1-j} \widehat{f}_{j}^{\prime \prime}-\widehat{f}_{n-1}^{\prime 2}+1 \\
& -\varepsilon\left(\widehat{f}_{n-1}^{\prime}-\frac{1}{2} \eta^{\prime \prime}{ }_{n-1}-1\right)+\frac{\sigma_{\mathrm{hnf}} / \sigma_{f}}{\rho_{\mathrm{hnf}} / \rho_{f}} M\left(E-\widehat{f}_{n-1}^{\prime}\right),
\end{aligned}
$$

$$
\begin{aligned}
\mathfrak{R}_{n}^{\hat{\theta}}(\eta)= & \frac{1}{\operatorname{Pr}} \frac{k_{\mathrm{hnf}} / k_{f}}{\left(\rho c_{p}\right)_{\mathrm{hnf}} /\left(\rho c_{p}\right)_{f}}\left(\widehat{\theta}^{\prime \prime}{ }_{n-1}\right)+\sum_{j=0}^{w-1} \widehat{\theta}_{w-1-f_{j}}^{\prime} \widehat{f}_{j} \\
& -2 \sum_{j=0}^{w-1} \widehat{\theta}_{w-1-j} \widehat{f}_{j}^{\prime}+\frac{\varepsilon}{2}\left(\eta \widehat{\theta}_{n-1}^{\prime}+3 \widehat{\theta}_{n-1}\right) \\
& +\frac{\sigma_{\mathrm{hnf}} / \sigma_{f}}{\left(\rho c_{p}\right)_{\mathrm{hnf}} / \rho_{f}} \operatorname{MEc}\left(\widehat{f}_{n-1}^{\prime}-E\right)+\frac{Q\left(\rho c_{p}\right)_{f}}{\left(\rho c_{p}\right)_{\mathrm{hnf}}} \widehat{\theta}_{n-1},
\end{aligned}
$$

with the condition

$$
\chi_{n}=\left\{\begin{array}{l}
0, \text { if } n \leq 1, \\
1, \text { if } n>1 .
\end{array}\right.
$$

\section{Results and Discussion}

The transformed equations of concentration, energy, and momentum (7) and (8) with the boundary condition (9) are solved using the homotopy analysis technique in this work. $\operatorname{Pr}, M, E, \varepsilon, \mathrm{Ec}$, and $Q$ are some of the parameters used in the computational analysis. $f^{\prime}(\eta)$ for the different embedded parameters, such as $E, M$ and $\varepsilon$, are shown in Figures 13 to highlight the influence of these input factors on the system.

Higher values of $E$ enhance the hybrid nanofluid velocity, as seen in Figure 1. An accelerating force is provided by an electric parameter. The stronger Lorentz force is connected with the higher value of $E$, whereas the weaker Lorentz force is related with the lower value of $E$ . The larger Lorentz force enhances and resolves the sticky effect caused by nanoparticles in the fluid, indicating an enhancement in convective heating transferred and the thickness of the momentum barrier layer. In Figure 2, we have shown the effect of $M$ on the hybrid nanofluid $f^{\prime}(\eta)$. In which, we observed that the thickness of the velocity and momentum boundary layers decreased as the magnetic parameter was raised. Lorentz flow is a resistive type force that occurs when a magnetic field is applied in the opposite flow direction. As a result, the fluid flow behavior becomes more resistive, resulting in a decline in $f^{\prime}(\eta)$ and a thickness boundary layer. In addition to this, we highlighted the impact of $\varepsilon$ on the nanofluid $f^{\prime}(\eta)$ in Figure 3.

Because of the acceleration situation $(\varepsilon>0)$, the hybrid nanofluid flow rate is slower, and the thickness of boundary layer of momentum is thinner. For enhanced acceleration, the $f^{\prime}(\eta)$ decreases. In Figures 4-9, we illustrated the effect of Ec, $E, Q, M, \varepsilon$, and $\operatorname{Pr}$ on $\theta(\eta)$. Figure 4 shows that the thickness of the thermal boundary layer and the nanofluid temperature are increased as the kinetic energy to enthalpy ratio rises with an enhance in the Ec values. In Figures 5 and 6, the influence of heat absorption or generation on $\theta(\eta)$ is highlighted numerically. The parameter $\theta(\eta)$ of the fluid and the thickness of the thermal boundary layer are both increased when $(Q>0)$ is used. 


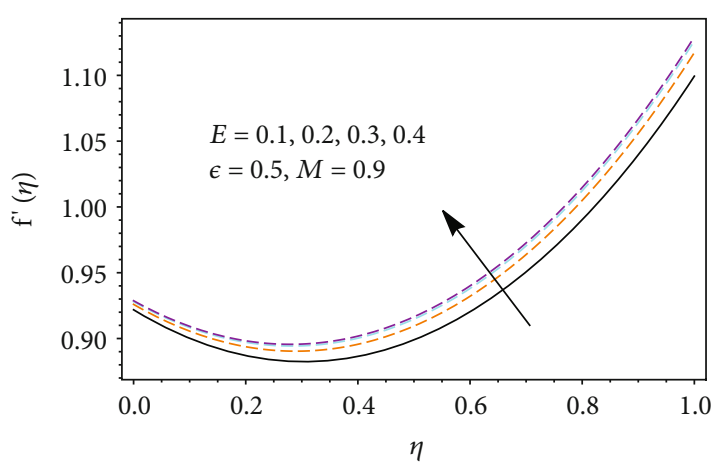

Figure 1: Illustration of the influence of $E$ on $f^{\prime}(\eta)$.

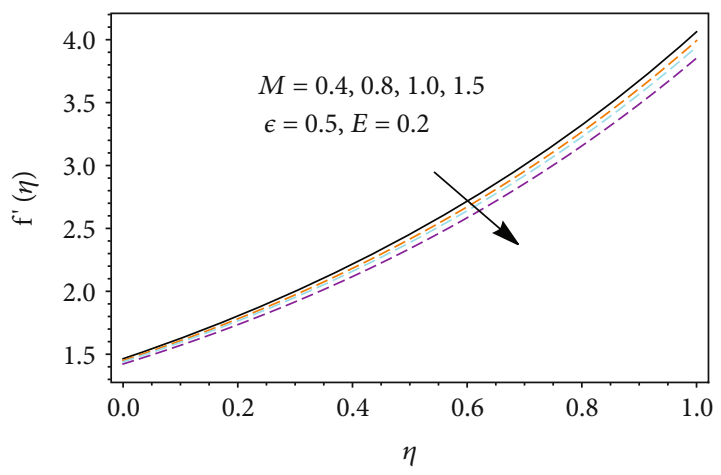

Figure 2: Illustration of the influence of $M$ on $f^{\prime}(\eta)$.

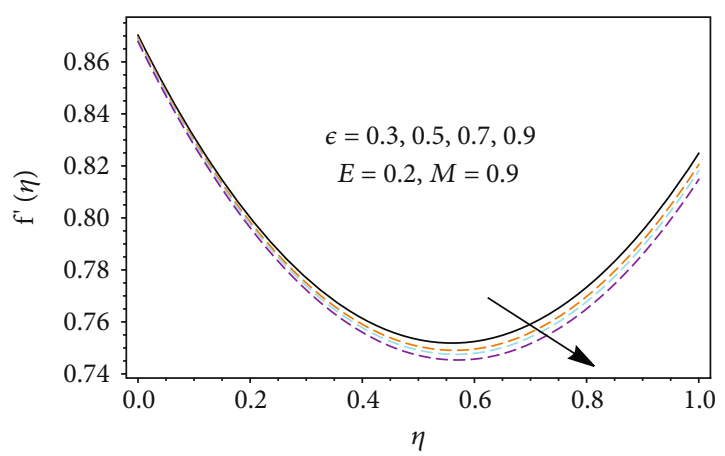

Figure 3: Illustration of the influence of the $\varepsilon$ on $f^{\prime}(\eta)$.

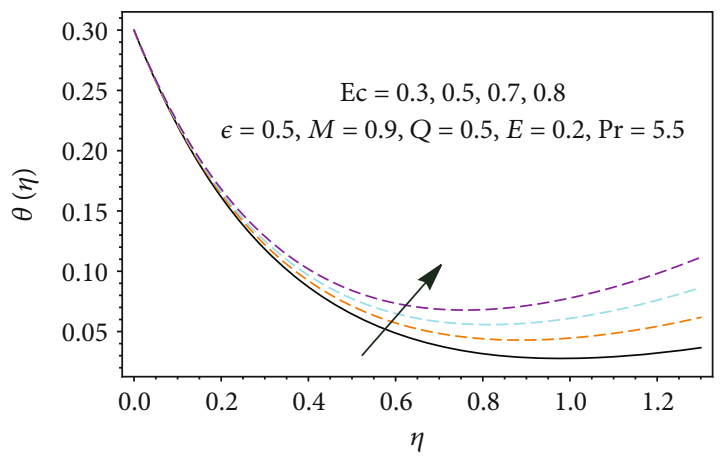

FIgURE 4: Illustration of the influence of Ec on $\theta(\eta)$.

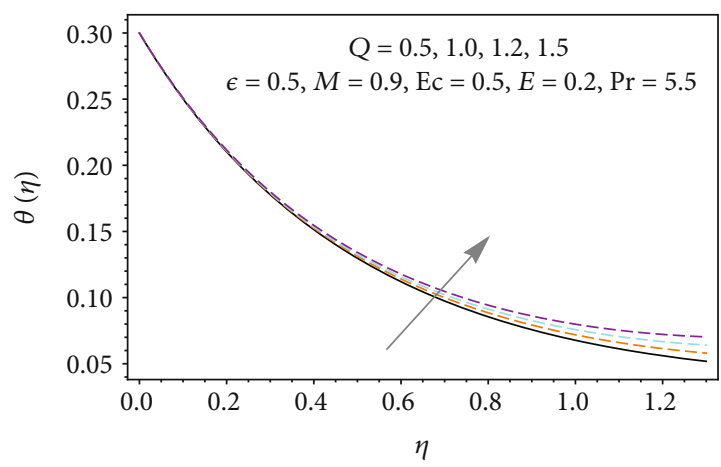

FIGURE 5: Illustration of the influence of the input factor $Q>0$ on $\theta(\eta)$.

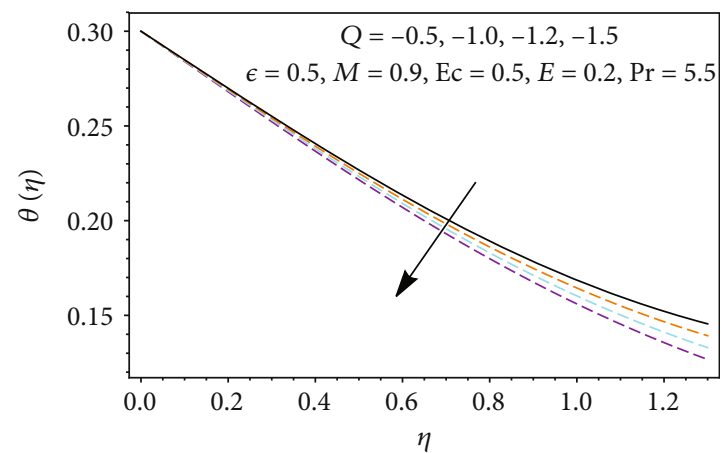

FIgURE 6: Illustration of the influence of the input factor $Q<0$ on $\theta(\eta)$.

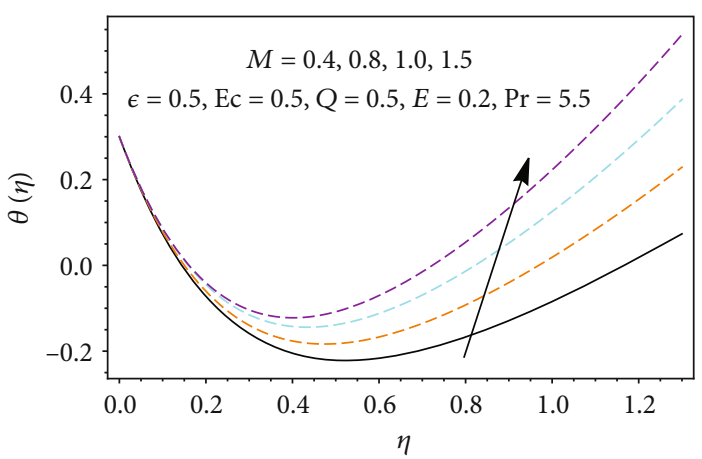

Figure 7: Illustration of the influence of $M$ on $\theta(\eta)$.

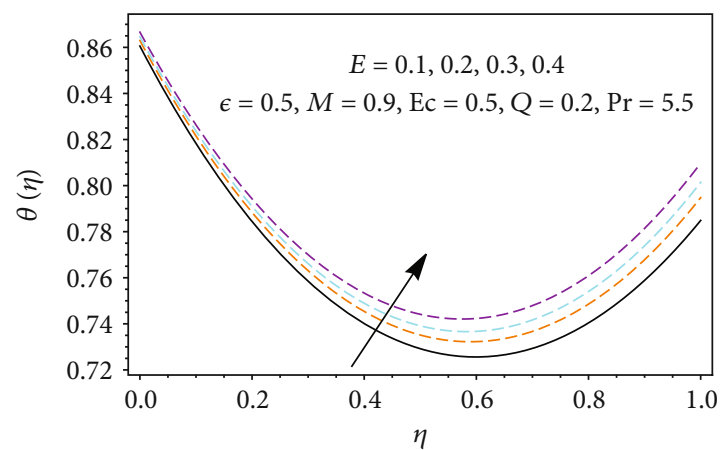

FIGURE 8: Illustration of the influence of the electric field parameter on temperature profile. 


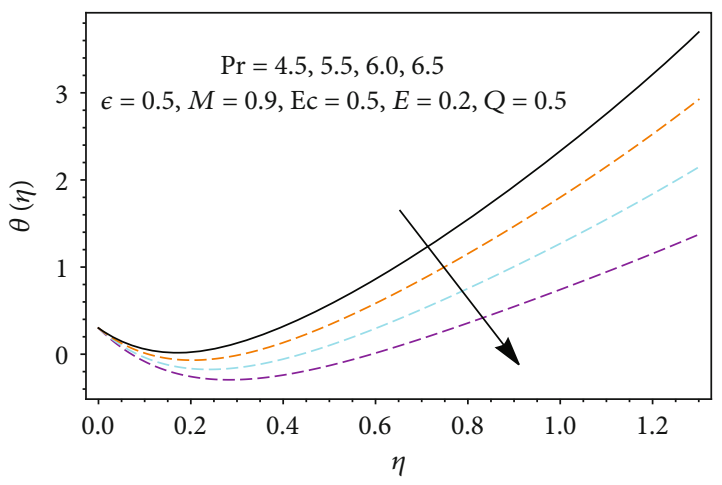

Figure 9: Illustration of the influence of the input factor $\operatorname{Pr}$ on $\theta(\eta)$

TABLE 3: Impact of different input factors on skin friction $\left[R_{e x}\right]^{1 / 2}$ $C_{f}=\left(\mu_{\mathrm{hnf}} / \mu_{f}\right) f^{\prime \prime}(0)$.

\begin{tabular}{cccc}
\hline$\varepsilon$ & $E$ & $\mathrm{M}$ & $\left(\mu_{\mathrm{hnf}} / \mu_{f}\right) f^{\prime \prime}(0)$ \\
\hline 0.3 & 0.1 & 0.4 & 0.72059328 \\
0.5 & & & 0.83542092 \\
0.7 & & & 1.03614135 \\
& 0.1 & & 1.86313569 \\
& 0.2 & & 1.64385204 \\
& 0.3 & 0.4 & 1.76103193 \\
& & 0.8 & 1.03873708 \\
& & 1.0 & 1.30863981 \\
& & & 1.58376213 \\
\hline
\end{tabular}

On the other hand, $(Q<0)$ outcomes in a lower fluid temperature and a smaller thickness of the thermal boundary layer. $Q=0$ denotes the lack of heat generation or absorption. Figure 7 reveals the impact of $M$ on $\theta(\eta)$ of the nanofluids. We noticed that the transverse magnetic field increases the thickness of the thermal boundary layer. As a result, the temperature of the fluid as well as the thickness of the thermal boundary layer increased. The magnetic field acts as a strong Lorentz force, increasing the temperature of the nanofluid in the boundary region. Figure 8 shows the depicts the impact of $E$ on $\theta(\eta)$.

The impact of $E$ on $\theta(\eta)$ is shown in Figure 8, which showed that the electric field acts as an accelerating force, raising the fluid flow temperature and increasing the thickness of the thermal boundary layer. A thicker, higher quantity temperature distribution within the boundary layer region of the hybrid nanofluid's vicinity is connected with a greater value of an electric field. The Prandtl number is a material property that varies depending on the fluid. From Figure 9, it reveals that as it raises in $\operatorname{Pr}, \theta(\eta$ ) declines. Moreover, the higher value of $\operatorname{Pr}$ implies smaller thermal diffusivity than the momentum diffusivity. As a result, the energy boundary layer thickness declines. Table 3 represents that $C_{f}$ is raised when the values of $M, \varepsilon$, and $E$ are increased. Table 4 shows that $N u_{x}$ is
TABLE 4: Impact of different input factors on the Nusselt number $\left[\left(-k_{\mathrm{hnf}} / k_{f}\right) \theta^{\prime}(0)\right]$.

\begin{tabular}{cccccc}
\hline Ec & $Q$ & Pr & $M$ & $E$ & $-\left(k_{\text {hnf }} / k_{f}\right) \theta^{\prime}(0)$ \\
\hline 0.3 & 0.5 & 4.5 & 0.4 & 0.1 & 1.07386504 \\
0.5 & & & & & 1.17290347 \\
0.7 & & & & & 1.23893104 \\
& 0.5 & & & & 2.30319769 \\
& 1.0 & & & & 2.15912307 \\
& 1.5 & & & & 2.02463073 \\
& & & & & 0.54354079 \\
& & 5.5 & & & 0.73865302 \\
& & & & & 0.93865321 \\
& & & & & 1.13159603 \\
& & 0.4 & & 1.09764384 \\
& & 1.0 & & 1.05346068 \\
& & & 0.1 & 1.12183304 \\
& & & 0.2 & 1.23583931 \\
& & & 0.3 & 1.30346893 \\
\hline
\end{tabular}

increased when the values of $M, Q$ are increased. The $N u_{x}$ is decreased, when the values of $\operatorname{Pr}, E$, and Ec is increased.

\section{Concluding Remarks}

This study investigates the unsteady electrohydrodynamic stagnation-point fluid flow of a hybrid nanofluid over a convective heat stretch or shrink sheet, taking into account the velocity slip effect on heat transferred. The effects of heat generation and absorption, as well as the electric and magnetic fields, are all taken into account. The following are the main observations of the present study:

(i) $f^{\prime}(\eta)$ and $\theta(\eta)$ raises with an enhance in the value of $E$

(ii) The magnetic factor has an inverse impact for velocity and temperature gradient

(iii) A heat source raises the temperature, whereas a heat sink does the opposite

(iv) The velocity and temperature are reduced at higher levels of the unsteadiness parameter

(v) The Eckert parameter shows an enhance in temperature, while Pr shows a reduction

(vi) Skin friction is raised when the values of $M, \varepsilon$, and $E$ are augmented

(vii) The Nusselt number is enlarged when the values $M, Q$ are increased, and $N u_{x}$ is diminished, when the values of $\operatorname{Pr}, E$, and Ec are enlarged 


\section{Nomenclature}

$u_{w}: \quad$ Stretched/shrinking velocity $(\mathrm{m} / \mathrm{s})$

$u$ and $v$ : Along $x$ - and $y$-axis velocity terms $(\mathrm{m} / \mathrm{s})$

$\left(\rho c_{p}\right)_{\mathrm{hnf}}$ : Volumetric heat capacity of hybrid nanofluid ( $\left.\mathrm{m}^{2} \mathrm{~s}^{-2} \mathrm{~K}^{-1}\right)$

$T_{1}: \quad$ Ambient temperature $(\mathrm{K})$

$h_{f}$ : Coefficient of heat transfer

$\mu_{\mathrm{hnf}}: \quad$ Hybrid nanofluid viscosity $\left(\mathrm{kgm}^{-1} \mathrm{~s}^{-1}\right)$

$k_{\text {hnf }}$ : Hybrid nanofluid thermal/heat conductivity

$\mathrm{Re}_{x}$ : Reynolds number

$H_{1}$ : $\quad$ Velocity slip factor

$\rho_{s}: \quad$ The density of the nanoparticle $\left(\mathrm{kgm}^{-3}\right)$

$\psi: \quad$ Stream function

Ec: $\quad$ Eckert number

Pr: $\quad$ Prandtl number

Bi: $\quad$ Biot number

$\mathrm{Nu}_{x}: \quad$ Local Nusselt number

$\lambda: \quad$ Ratio of velocity parameter and heat

$f^{\prime}$ : Dimensionless velocity

$v$ : $\quad$ Kinematic viscosity $\left(\mathrm{m}^{2} \mathrm{~s}^{-1}\right)$

$\phi: \quad$ Nanoparticle solid volume fraction

$x, y: \quad$ Plane coordinate axis

$u_{e}$ : $\quad$ Strength of the stagnation flow

$\rho_{f}: \quad$ Basie fluid density $\left(\mathrm{kgm}^{-3}\right)$

$T_{0}: \quad$ Reference temperature $(\mathrm{K})$

$\rho_{\text {hnf }}: \quad$ Hybrid nanofluid density $\left(\mathrm{kgm}^{-3}\right)$

$k_{s}: \quad \quad \quad$ Nanoparticle thermal conductivity $\left(\mathrm{Wm}^{-1} \mathrm{~K}^{-1}\right)$

$\eta$ : $\quad$ Similarity variable

$H$ : Initial value of the velocity slip factor

$c_{p}: \quad$ Heat capacity constant pressure

$k_{f}$ : $\quad$ Base fluid thermal conductivity $\left(\mathrm{Wm}^{-1} \mathrm{~K}^{-1}\right)$

$\varepsilon$ : $\quad$ Unsteadiness parameter

$E: \quad$ Electric field parameter

M: $\quad$ Magnetic parameter

Q: $\quad$ Source/sink parameter.

$c_{f}$ : Coefficient of skin friction

$\mu_{f}: \quad$ Dynamic viscosity $\left(\mathrm{kgm}^{-1} \mathrm{~s}^{-1}\right)$

T: $\quad$ Temperature of fluid $(K)$

$\tau_{w}: \quad$ Wall shear stress

$q_{w}: \quad$ Transportation of heat.

\section{Data Availability}

No data were used to support the study.

\section{Conflicts of Interest}

The authors declare that they have no conflicts of interest.

\section{Acknowledgments}

The sixth named author extends appreciation to the Deanship of Scientific Research at King Khalid University for funding this work through research groups program under grant (RGP2/53/42).

\section{References}

[1] S. P. A. Devi and S. S. U. Devi, "Numerical investigation of hydromagnetic hybrid $\mathrm{Cu}-\mathrm{Al}_{2} \mathrm{O}_{3} /$ Water nanofluid flow over a permeable stretching sheet with suction," International Journal of Nonlinear Sciences and Numerical Simulation, vol. 17, no. 5, pp. 249-257, 2016.

[2] S. S. U. Devi and S. P. A. Devi, "Numerical investigation of three-dimensional hybrid $\mathrm{Cu}-\mathrm{Al}_{2} \mathrm{O}_{3}$ /water nanofluid flow over a stretching sheet with effecting Lorentz force subject to Newtonian heating," Canadian Journal of Physics, vol. 94, no. 5, pp. 490-496, 2016.

[3] T. HAYAT and S. NADEEM, "Heat transfer enhancement with Ag-CuO/water hybrid nanofluid," Results in Physics, vol. 7, pp. 2317-2324, 2017.

[4] N. A. Zainal, R. Nazar, K. Naganthran, and I. Pop, "Unsteady stagnation point flow of hybrid nanofluid past a convectively heated stretching/shrinking sheet with velocity slip," Mathematics, vol. 8, no. 10, pp. 1649-1722, 2020.

[5] Y. S. Daniel, Z. A. Aziz, Z. Ismail, and F. Salah, "Double stratification effects on unsteady electrical MHD mixed convection flow of nanofluid with viscous dissipation and Joule heating," Journal of Applied Research and Technology, vol. 15, no. 5, pp. 464-476, 2017.

[6] H. Xie, B. Jiang, B. Liu, Q. Wang, J. Xu, and F. Pan, "An investigation on the tribological performances of the SiO2/MoS2 hybrid nanofluids for magnesium alloy-steel contacts," Nanoscale Research Letters, vol. 11, no. 1, pp. 329-336, 2016.

[7] M. Afrand, D. Toghraie, and B. Ruhani, "Effects of temperature and nanoparticles concentration on rheological behavior of $\mathrm{Fe}_{3} \mathrm{O}_{4}$-Ag/EG hybrid nanofluid: an experimental study," Experimental Thermal and Fluid Science, vol. 77, pp. 38-44, 2016.

[8] S. S. Ghadikolaei, M. Yassari, H. Sadeghi, K. Hosseinzadeh, and D. D. Ganji, "Investigation on thermophysical properties of $\mathrm{Tio}_{2}-\mathrm{Cu} / \mathrm{H}_{2} \mathrm{O}$ hybrid nanofluid transport dependent on shape factor in MHD stagnation point flow," Powder Technology, vol. 322, pp. 428-438, 2017.

[9] S. Hussain, S. E. Ahmed, and T. Akbar, "Entropy generation analysis in MHD mixed convection of hybrid nanofluid in an open cavity with a horizontal channel containing an adiabatic obstacle," International Journal of Heat and Mass Transfer, vol. 114, pp. 1054-1066, 2017.

[10] M. Waqas, M. Farooq, M. I. Khan, A. Alsaedi, T. Hayat, and T. Yasmeen, "Magnetohydrodynamic (MHD) mixed convection flow of micropolar liquid due to nonlinear stretched sheet with convective condition," International Journal of Heat and Mass Transfer, vol. 102, pp. 766-772, 2016.

[11] G. Zhao, Y. Jian, and F. Li, "Streaming potential and heat transfer of nanofluids in microchannels in the presence of magnetic field," Journal of Magnetism and Magnetic Materials, vol. 407, pp. 75-82, 2016.

[12] D. Yadav, J. Wang, R. Bhargava, J. Lee, and H. H. Cho, "Numerical investigation of the effect of magnetic field on the onset of nanofluid convection," Applied Thermal Engineering, vol. 103, pp. 1441-1449, 2016.

[13] A. J. Chamkha, A. M. Rashad, E. R. EL-Zahar, and H. A. ELMky, "Analytical and numerical investigation of $\mathrm{Fe}_{3} \mathrm{O}_{4}$-water nanofluid flow over a moveable plane in a parallel stream with high suction," Energies, vol. 12, no. 1, pp. 198-198, 2019.

[14] S. M. M. el-Kabeir, E. R. el-Zahar, M. Modather, R. S. Gorla, and A. M. Rashad, "Unsteady MHD slip flow of a ferrofluid 
over an impulsively stretched vertical surface," AIP Advances, vol. 9, no. 4, article 045112, 2019.

[15] L. J. Crane, "Flow past a stretching plate," Zeitschrift für angewandte Mathematik und Physik ZAMP, vol. 21, no. 4, pp. 645647, 1970.

[16] N. Sandeep, C. Sulochana, and B. Rushi Kumar, "Unsteady MHD radiative flow and heat transfer of a dusty nanofluid over an exponentially stretching surface," Engineering Science and Technology, an International Journal, vol. 19, no. 1, pp. 227-240, 2016.

[17] M. K. Nayak, N. S. Akbar, D. Tripathi, Z. H. Khan, and V. S. Pandey, "MHD 3D free convective flow of nanofluid over an exponentially stretching sheet with chemical reaction," Advanced Powder Technology, vol. 28, no. 9, pp. 2159-2166, 2017.

[18] T. Hayat and S. Nadeem, "Flow of 3D Eyring-Powell fluid by utilizing Cattaneo-Christov heat flux model and chemical processes over an exponentially stretching surface," Results in Physics, vol. 8, pp. 397-403, 2018.

[19] F. U. Rehman, S. Nadeem, and R. U. Haq, "Heat transfer analysis for three-dimensional stagnation-point flow over an exponentially stretching surface," Chinese Journal of Physics, vol. 55, no. 4, pp. 1552-1560, 2017.

[20] E. Magyari and B. Keller, "Heat and mass transfer in the boundary layers on an exponentially stretching continuous surface," Journal of Physics D: Applied Physics, vol. 32, no. 5, pp. 577-585, 1999.

[21] A. Mushtaq, M. A. Farooq, R. Sharif, and M. Razzaq, "The impact of variable fluid properties on hydromagnetic boundary layer and heat transfer flows over an exponentially stretching sheet," Journal of Physics Communications, vol. 3, no. 9, article 095005, 2019.

[22] G. B. Reddy, B. S. Goud, and M. R. Shekar, "Numerical solution of MHD mixed convective boundary layer flow of a nanofluid through a porous medium due to an exponentially stretching sheet with magnetic field effect," International Journal of Applied Engineering Research, vol. 14, pp. 2074-2083, 2019.

[23] A. N. H. Rahman, N. Bachok, and H. Rosali, "Numerical solutions of MHD stagnation-point flow over an exponentially stretching/shrinking sheet in a nanofluid," Journal of Physics: Conference Series, vol. 1366, article 012012, 2019.

[24] K. Hiemenz, "Die grenzschicht an einem in den gleichformigen flussigkeitsstrom eingetauchten geraden kreiszylinder," Dingler's Polytechnisches Journal, vol. 326, pp. 321-410, 1911.

[25] F. Homann, "Der Einfluß großer Zähigkeit bei der Strömung um den zylinder und um die kugel," Zeitschrift für Angewandte Mathematik und Mechanik, vol. 16, no. 3, pp. 153-164, 1936.

[26] K. L. Hsiao, "Stagnation electrical MHD nanofluid mixed convection with slip boundary on a stretching sheet," Applied Thermal Engineering, vol. 98, no. 5, pp. 850-861, 2016.

[27] N. Bachok, A. Ishak, and I. Pop, "Melting heat transfer in boundary layer stagnation-point flow towards a stretching/shrinking sheet," Physics letters A, vol. 374, no. 40, pp. 40754079, 2010.

[28] S. J. Liao, "On the homotopy analysis method for nonlinear problems," Applied Mathematics and Computation, vol. 147, no. 2, pp. 499-513, 2004.

[29] N. Nasir, Z. Shah, S. Islam, E. Bonyah, and T. Gul, "Darcy Forchheimer nanofluid thin film flow of SWCNTs and heat trans- fer analysis over an unsteady stretching sheet," AIP Advances, vol. 9, no. 1, article 015223, 2019.

[30] I. Tlili, W. A. Khan, and I. Khan, "Multiple slips effects on MHD SA- $\mathrm{Al}_{2} \mathrm{O}_{3}$ and SA-Cu non-Newtonian nanofluids flow over a stretching cylinder in porous medium with radiation and chemical reaction," Results in physics, vol. 8, pp. 213$222,2018$.

[31] N. S. Khan, Z. Shah, S. Islam, I. Khan, T. A. Alkanhal, and I. Tlili, "Entropy generation in MHD mixed convection nonNewtonian second-grade nanoliquid thin film flow through a porous medium with chemical reaction and stratification," Entropy, vol. 21, no. 2, article e21020139, p. 139, 2019.

[32] M. Fiza, S. Islam, H. Ullah, Z. Shah, and F. Chohan, “An asymptotic method with applications to nonlinear coupled partial differential equations," Punjab University Journal of Mathematics, vol. 50, pp. 139-151, 2018.

[33] N. Mezouar and S. M. Boulaaras, "Global existence and decay of solutions of a singular nonlocal viscoelastic system with damping terms," Topological Methods in Nonlinear Analysis, vol. 56, no. 1, pp. 1-312, 2020.

[34] S. M. Boulaaras, A. Choucha, A. Zara, M. Abdalla, and B. B. Cheri, "Global existence and decay estimates of energy of solutions for a new class of -Laplacian heat equations with logarithmic nonlinearity," Journal of Function Spaces, vol. 2021, Article ID 5558818, 11 pages, 2021.

[35] S. M. Boulaaras and M. Haiour, "The finite element approximation of evolutionary Hamilton-Jacobi-Bellman equations with nonlinear source terms," Indagationes Mathematicae, vol. 24, no. 1, pp. 161-173, 2013.

[36] S. M. Boulaaras, "Some new properties of asynchronous algorithms of theta scheme combined with finite elements methods for an evolutionary implicit 2-sided obstacle problem," Mathematical Methods in the Applied Sciences, vol. 40, no. 18, pp. 7231-7239, 2017.

[37] S. Khattak, I. Hussain, J. F. Gomez-Aguilar, and R. Jan, “Analysis of PD-type iterative learning control for discrete-time singular system," Mathematical Methods in the Applied Sciences, 2021.

[38] S. Toualbia, A. Zaraï, and S. M. Boulaaras, "Decay estimate and non-extinction of solutions of $\mathrm{p}$-Laplacian nonlocal heat equations," AIMS Mathematics, vol. 5, no. 3, pp. 1663-1679, 2020.

[39] W. U. Jan, M. Farooq, R. A. Shah, A. Khan, M. S. Zobaer, and R. Jan, "Flow dynamics of the homogeneous and heterogeneous reactions with an internal heat generation and thermal radiation between two squeezing plates," Mathematics, vol. 9, no. 18, p. 2309, 2021.

[40] K. Hosseini, M. Ilie, M. Mirzazadeh, and D. Baleanu, “An analytic study on the approximate solution of a nonlinear timefractional Cauchy reaction-diffusion equation with the Mittag-Leffler law," Mathematical Methods in the Applied Sciences, vol. 44, no. 8, pp. 6247-6258, 2021. 